\title{
Modulation of Systemic and Aortic Nitric Oxide by Melatonin and n-3 Polyunsaturated Fatty Acids in Isoproterenol Affected Spontaneously Hypertensive and Normotensive Wistar Rats
}

\author{
K. K. CHAUDAGAR ${ }^{1,2}$, C. VICZENCZOVA ${ }^{1}$, B. SZEIFFOVA BACOVA ${ }^{1}$, \\ T. EGAN BENOVA ${ }^{1}$, M. BARANCIK ${ }^{1}$, N. TRIBULOVA ${ }^{1}$ \\ ${ }^{1}$ Institute for Heart Research, Slovak Academy of Sciences, Bratislava, Slovak Republic, \\ ${ }^{2}$ L. M. College of Pharmacy, Ahmedabad, India
}

Received June 10, 2016

Accepted June 24, 2016

\begin{abstract}
Summary
We aimed to explore the effects of melatonin and $n-3$ polyunsaturated fatty acids (PUFA) supplementation on plasma and aortic nitric oxide (NO) levels in isoproterenol (Iso) affected spontaneously hypertensive (SHR) and Wistar rats. Untreated control rats were compared with Iso injected $(118 \mathrm{mg} / \mathrm{kg}$, s.c.) rats, and Iso injected plus supplemented with melatonin (10 mg/kg, p.o.) or PUFA (1.68 g/kg, p.o.) for two months. Plasma and aortic basal, L-NAME inhibited, adrenaline and acetylcholine stimulated NO were determined using Griess method. Plasma NO levels were lower in SHR versus Wistar rats. Iso decreased NO in Wistar while not in SHR. PUFA but not melatonin intake of Iso treated SHR increased plasma NO along with a decrease in systolic blood pressure. Basal aortic NO level was higher in SHR than Wistar rats and not altered by Iso. Intake of melatonin increased but PUFA decreased basal NO levels in Wistar+Iso and did not affect in SHR+Iso rats. Acetylcholine and adrenaline induced aortic NO release was significantly increased in Wistar+Iso but not SHR+Iso group. Melatonin intake increased Ach induced aortic NO in Wistar+Iso and SHR+Iso groups, whereas there was no effect of PUFA intake. Findings suggest that PUFA modulates plasma and melatonin aortic NO levels of isoproterenol affected rats in a strain-dependent manner.
\end{abstract}

\section{Key words}

Nitric oxide • Melatonin • Polyunsaturated fatty acid • Aorta • Plasma

\section{Corresponding author}

N. Tribulova, Institute for Heart Research, Slovak Academy of Sciences, Dubravska cesta 9, P.O.Box 104, 84005 Bratislava, Slovak Republic. E-mail: narcisa.tribulova@savba.sk

\section{Introduction}

Nitric oxide (NO) is a gaseous signaling mediator that plays a significant role in vascular homeostasis such as vasodilation, endothelial proliferation, survival and angiogenesis. $\mathrm{NO}$ is biosynthesized from L-arginine by enzymatic action of nitric oxide synthase (NOS) and, by non-enzymatic way, produced from nitrate, nitrite and S-nitrosothiol products (Zhao et al. 2015). There is an inverse relationship between NO bioavailability and severity of hypertension. In a clinical study, the generalized endothelial abnormality was found in NO release and its accomplishment with the increased of blood pressure (Panza et al. 1995). In hypertensive subjects, the loss of NO bioavailability in response to acetylcholine (Ach) was primarily related to lack of NOS mediated NO biosynthesis, scarcity of functional endothelial cells and degradation of NO by reactive oxygen species (Púzserová et al. 2013, Taddei et al. 1997, Vázquez-Pérez et al. 2001). Similar to Ach, norepinephrine and isoproterenol (Iso) induced endothelial NO release was also abolished in hypertensive animals, whereas contractile response of norepinephrine was increased (Arribas et al. 1994, Vázquez-Pérez et al. 2001). However, reports have been suggesting similarity in endothelium independent vasodilation between normotensive and hypertensive humans (Panza et al. 1995, Taddei et al. 1997). Therefore, the restoration of endothelial NO release is a key component for the treatment of hypertension and related vascular abnormalities. 
Among all cardiovascular diseases, $5 \%$ of death pertains to hypertensive heart diseases (Mendis et al. 2011). Spontaneously hypertensive rats (SHR) were more vulnerable to ventricular fibrillation induction than normotensive Wistar rats (Benova et al. 2013). The cardiac $\beta$-adrenoceptor signaling and NO mediated relaxation responses were abolished in SHR but not in Wistar rats (Manso et al. 2000). These data suggest development of cardiac abnormalities due to hypertension. Other than this, vasomotor tone is also disturbed by cardiac pathology. Coronary artery ligation induced heart failure in rats caused impairment of endothelium dependent NO response in mesenteric arteries and pulmonary arteries (Baggia et al. 1997). Heart failure decreased $\beta$-adrenoceptor density in the aorta by increasing G-protein coupled receptor kinase activity (Gaballa et al. 2001). High dose of Iso, $\beta$-adrenoceptor agonist, is widely used for induction of myocardial infarction and heart failure in rats (Zhang $\mathrm{G}$ et al. 2005, Zhang J et al. 2008). However, adverse effects of Iso on vasculature and NO formation are less explored and data about efficiency of treatment is missing.

Melatonin and PUFA are well known for their cardio-protective and anti-hypertensive action (Benova et al. 2013, Borghi et al. 2006, Radosinska et al. 2011, Simko et al. 2007). Melatonin increased Ach induced vasodilation and NO release by local (from endothelial cells of aorta) and systemic (increasing L-arginine production from kidney) actions in SHR (Girouard et al. 2001, Tain et al. 2010). In a previous study (Dlugosova et al. 2009), treatment with PUFA significantly increased aortic NOS activity and decreased blood pressure in SHR. Surprisingly, PUFA did not enhance Ach induced vasodilatation in aorta. Anti-hypertensive action of melatonin and PUFA is attributed to multiple mechanisms such as anti-oxidant properties, downregulation of adrenoceptor signaling, and intracellular calcium modulation (Engler et al. 2000, K-Laflamme et al. 1998, Lawson et al. 1991, Mano et al. 1995, Pechánová et al. 2007, Pogan et al. 2002).

The aim of this study was to explore the effects of melatonin and PUFA supplementation on plasma and aortic basal as well as stimulated NO levels in high Iso dose affected male, 8-month-old SHR and normotensive Wistar rats.

\section{Methods}

Animal experiments were performed in accordance with the rules issued by the State Veterinary Administration of the Slovak Republic, legislation No. 377/2012 and they conform to the 'European Convention for the Protection of Vertebrate Animals used for Experimental and other Scientific Purposes' (Council of Europe No 123, Strasbourg 1985). Adult, male (8-month-old) SHR and age matched normotensive Wistar rats (WR) were used. Rats were divided into four groups ( $n=6$ per group), untreated control rats (WC and SC), isoproterenol (Iso) injected rats (WI and SI), melatonin + isoproterenol treated rats (WIM and SIM), and n-3 polyunsaturated fatty acids (PUFA) + isoproterenol treated rats (WIO and SIO). Iso was injected subcutaneously for 7 days in graded manner from $7 \mathrm{mg} / \mathrm{kg}$ to $30 \mathrm{mg} / \mathrm{kg}$ (Fig. 1). Melatonin (10 mg/kg/day during 67 days) was given in drinking water at night time. PUFA ( $1.68 \mathrm{~g} / \mathrm{kg} /$ day, i.e. $2 \mathrm{ml} / \mathrm{kg}$, during 67 days using Omacor, $46 \%$ eicosapentaenoic acid $+38 \%$ docosahexaenoic acid ethyl ester, Pronova Biopharma Norge AS, Norway) was administered by gastric tube. Untreated control rats were handled with drinking water and saline injection.

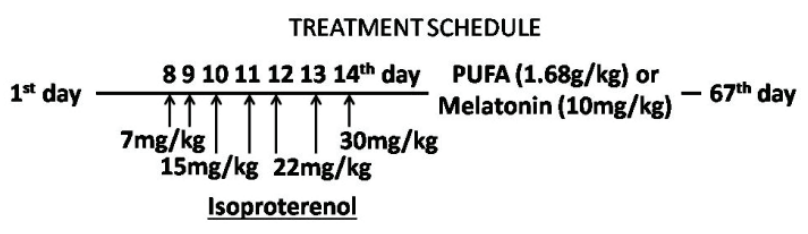

Fig. 1. Schedule of melatonin, PUFA and isoproterenol administration to normotensive Wistar rats and SHR. Experiment started at $1^{\text {st }}$ and ended after 67 days. Iso was injected within 7 days from $7 \mathrm{mg} / \mathrm{kg}$ to $30 \mathrm{mg} / \mathrm{kg}$.

Systolic blood pressure and body weight were determined on the $1^{\text {st }}$ day and the last $67^{\text {th }}$ day. Systolic blood pressure was measured by tail-cuff plethysmography using the Statham Pressure Transducer P23XL (Hugo Sachs, Germany). At the end of experiment, the chest of euthanized rats was opened and blood sample and aorta were processed. Aorta was excised, dissected and cut into $1 \mathrm{~mm}$ rings and divided into six subgroups to examine NO levels using Griess method in all groups of rats. Nitrite was detected and analyzed by formation of a red pink color upon treatment of a $\mathrm{NO}^{2-}$ containing sample with the Griess reagent.

1) Basal NO determination: Aortic ring incubated in modified Krebs-Henseleit (K-H) buffer $\left(200 \mu \mathrm{l}, 118.5 \mathrm{mM} \mathrm{NaCl}, 4.7 \mathrm{mM} \mathrm{KCl}, 1.2 \mathrm{mM} \mathrm{CaCl}_{2}\right.$, $4.7 \mathrm{mM} \mathrm{MgSO}, 11 \mathrm{mM}$ glucose, $25 \mathrm{mM} \mathrm{NaHCO}$, and

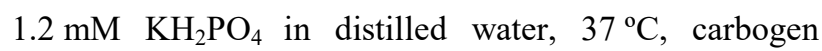
(mixture of $5 \% \mathrm{CO}_{2}$ and $95 \% \mathrm{O}_{2}$ for $30 \mathrm{~min}$ ). 
2) $\mathrm{N}^{\mathrm{G}}$-nitro-L-arginine methyl ester (L-NAME, L-N) NO determination: Aortic ring incubated in the K-H buffer $(100 \mu \mathrm{l})$ containing L-NAME $\left(10^{-4} \mathrm{M}\right.$, NOS inhibitor, $15 \mathrm{~min})$, and later in the K-H buffer $(100 \mu \mathrm{l})$ for $15 \mathrm{~min}$.

3) Acetylcholine (Ach) stimulated NO determination: Aortic ring incubated in the K-H buffer $(100 \mu \mathrm{l})$ for $15 \mathrm{~min}$, and later in the K-H buffer $(100 \mu \mathrm{l})$ containing acetylcholine $\left(10^{-6} \mathrm{M}, 15 \mathrm{~min}\right)$.

4) Adrenaline (Adr) NO determination: Aortic ring incubated in the K-H buffer $(100 \mu \mathrm{l})$ for $15 \mathrm{~min}$, and later in the K-H buffer $(100 \mu \mathrm{l})$ containing adrenaline $\left(10^{-6} \mathrm{M}, 15 \mathrm{~min}\right)$.

5) L-N + Ach NO: Aortic ring incubated in the K-H buffer $(100 \mu \mathrm{l})$ containing L-NAME $\left(10^{-4} \mathrm{M}\right.$, $15 \mathrm{~min})$, and later in the K-H buffer $(100 \mu \mathrm{l})$ containing acetylcholine $\left(10^{-6} \mathrm{M}, 15 \mathrm{~min}\right)$.

6) L-N + Adr NO: Aortic ring incubated in the $\mathrm{K}-\mathrm{H}$ buffer $(100 \mu \mathrm{l})$ containing L-NAME $\left(10^{-4} \mathrm{M}\right.$, $15 \mathrm{~min})$, and later in the K-H buffer (100 $\mu \mathrm{l})$ containing adrenaline $\left(10^{-6} \mathrm{M}, 15 \mathrm{~min}\right)$.

After the second incubation, $50 \mu$ of supernatant from each subgroup was mixed with $\mathrm{VCl}_{3}(30 \mu \mathrm{l})$ and Griess reagent $(50 \mu \mathrm{l}$, freshly prepared by mixing sulphanilamide $2 \%$, N-(1-naphthyl)-ethylenediamine, $0.2 \%$ and orthophosphoric acid) for color development (30 min). Absorbance was estimated at $550 \mathrm{~nm}$ using ELISA reader (Chaudagar et al. 2014). The intensity of purple color indicated the amount of NO in the samples.

For systemic NO determination, blood was collected from thoracic cavity into heparinized tubes after dissecting aorta. Tubes were centrifuged $\left(4^{\circ} \mathrm{C}, 1000 \mathrm{~g}\right.$, $10 \mathrm{~min}$ ) to separate plasma. $50 \mu \mathrm{l}$ of plasma was used for NO determination using Griess method as mentioned earlier.

\section{Statistical analysis}

All values were presented as mean \pm SEM. Graphpad Prism software (version 5.0, Graph Pad software Inc, USA) was used for statistical analyses. Body weight, systolic blood pressure and L-NAME pertain NO releasing data were analyzed by student $t$-test. Other data were interpreted using one way ANOVA test, followed by Bonferroni correction. A value of $p<0.05$ was considered to be statistically significant.

\section{Results}

Registered biometrical parameters showed a significant $(\mathrm{p}<0.01)$ increase in systolic blood pressure and a decrease in body weight of 8-month-old SHR when compared to age matched normotensive Wistar rats (Table 1). On the $67^{\text {th }}$ day (the end of experiment, Fig. 1), there were no significant changes in systolic blood pressure of untreated SHR and Wistar rats when compared to the $1^{\text {st }}$ day. There was no change in systolic blood pressure of SHR and normotensive Wistar rats injected by isoproterenol as well as melatonin + isoproterenol rats when compared to untreated ones. In contrast, PUFA intake of isoproterenol injected rats resulted in decrease $(\mathrm{p}<0.05)$ in systolic blood pressure of SHR but not Wistar rats when compared to the $1^{\text {st }}$ day (Fig. 2).

Table 1. Phenotypic characteristics of adult male 8-month-old SHR and age matched normotensive Wistar rats.

\begin{tabular}{lcc}
\hline Phenotypes & Wistar rats & SHR \\
\hline $\begin{array}{l}\text { Body weight }(g) \\
\text { Systolic blood } \\
\text { pressure (mm Hg) }\end{array}$ & $286 \pm 3.586$ & $270.7 \pm 2.66^{* *}$ \\
\hline
\end{tabular}

Values are expressed as mean $\pm \operatorname{SEM}(n=33) .{ }^{* *} p<0.01$ and ${ }^{* * *} p<0.001$ vs. Wistar rats.

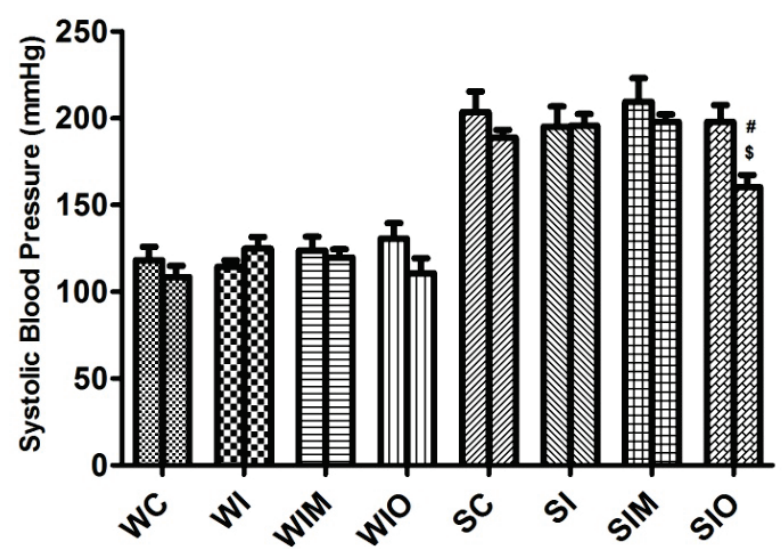

Fig. 2. Systolic blood pressure of experimental animals at the begining (first column) and end (second column); untreated Wistar rats (WC), isoproterenol (Iso) treated WR (WI), melatonin + Iso treated WR (WIM), PUFA + Iso treated WR (WIO), untreated SHR (SC), Iso treated SHR (SI), melatonin + Iso treated SHR (SIM) and PUFA + Iso treated SHR (SIO). Values are expressed as mean \pm SEM. ${ }^{\$} p<0.05$ vs. starting value in each group. ${ }^{\#} \mathrm{p}<0.05$ vs. respective SC column. Systolic blood pressure of SHR columns is significantly $(p<0.001)$ higher than respective WR columns.

Compared to normotensive Wistar rats, SHR exhibited significantly $(\mathrm{p}<0.05)$ lower plasma NO levels. 
Isoproterenol injection of Wistar rats resulted in significant $(p<0.01)$ decrease of plasma NO level when compared to untreated ones. This decrease was not affected by supplementation with either PUFA or melatonin (Fig. 3A). In contrast, there was no change in plasma NO of SHR due to isoproterenol administration. PUFA supplementation but not melatonin increased $(\mathrm{p}<0.05)$ plasma NO level in SHR when compared to untreated or isoproterenol injected SHR (Fig. 3A).
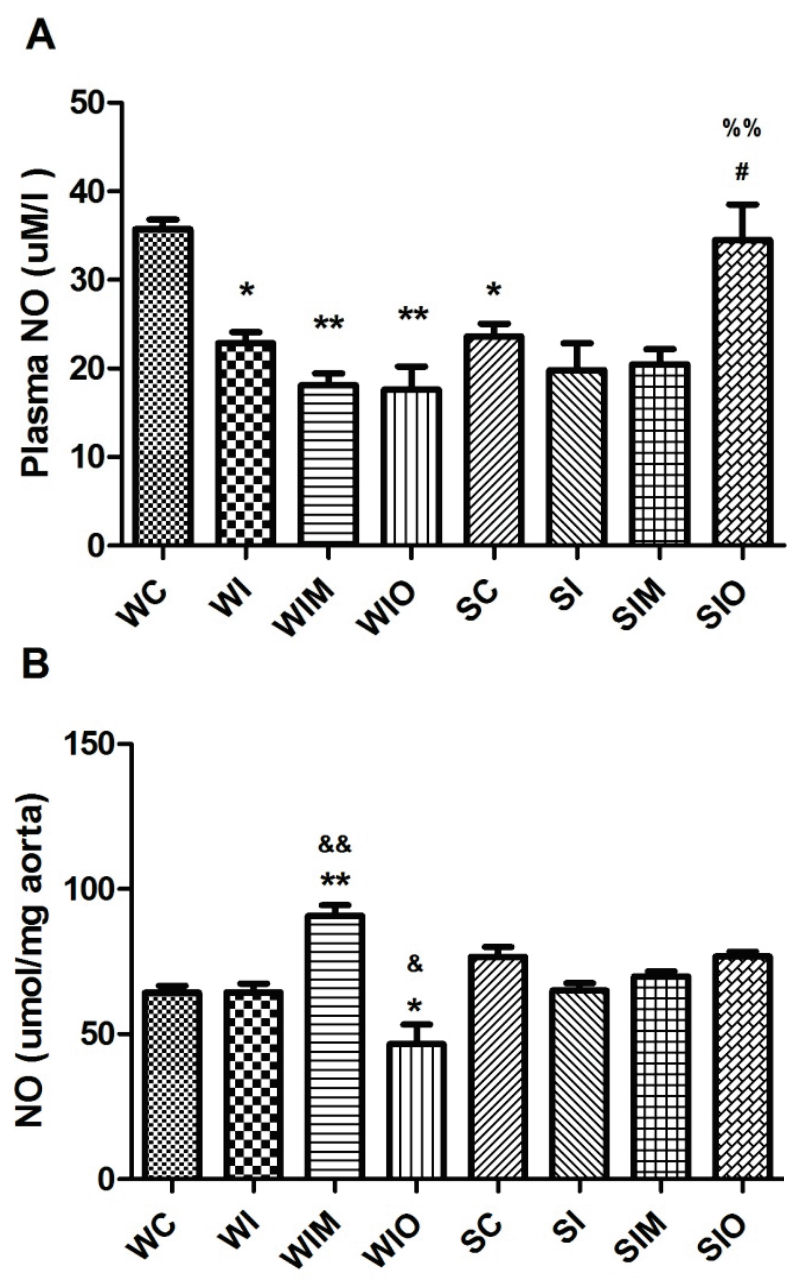

Fig. 3. (A) Plasma NO level and (B) basal aortic NO release of experimental animals; untreated Wistar rats (WC), isoproterenol (Iso) treated WR (WI), melatonin + Iso treated WR (WIM), PUFA + Iso treated WR (WIO), untreated SHR (SC), Iso treated SHR (SI), melatonin + Iso treated SHR (SIM) and PUFA + Iso treated SHR (SIO). Values are expressed as mean \pm SEM. $* p<0.05$, $* * p<0.01$ and $* * * p<0.001$ vs. WC. ${ }^{\&} p<0.05$ and ${ }^{8 \&} p<0.01$ vs. WI. ${ }^{\#} p<0.05$ vs. SC. ${ }^{\%} \% p<0.01$ vs. SI.

Basal aortic NO (data are summarized in Fig. 3B) was slightly but not significantly increased in untreated SHR when compared to untreated Wistar rats.
There was no change in basal aortic NO level between untreated and isoproterenol affected SHR or Wistar rats. On the other hand, basal aortic NO was significantly increased by melatonin intake of isoproterenol injected Wistar rats. In contrast, basal aortic NO was significantly decreased by PUFA intake of isoproterenol injected Wistar rats when compared to untreated and isoproterenol-injected normotensive rats. Neither melatonin nor PUFA did affect the basal aortic NO in SHR comparing to untreated and isoproterenol affected SHR.

Compared to basal condition, adrenaline and acetylcholine stimulated aortic NO levels were significantly $(\mathrm{p}<0.05)$ increased in untreated as well as isoproterenol affected normotensive Wistar rats, while reversed by NOS inhibitor, L-NAME (Fig. 4A,B). This significant adrenaline and acetylcholine mediated aortic NO release was not registered in untreated and isoproterenol treated SHR (Fig. 5A,B). Treatment of isoproterenol affected rats with melatonin (Fig. 4C, Fig. 5C) resulted in significant $(p<0.05)$ increase in acetylcholine mediated NO release from the aorta of both SHR and normotensive Wistar rats. This release was suppressed by L-NAME. Treatment of isoproterenol affected rats with PUFA (Fig. 4D, Fig. 5D) did not affect adrenaline or acetylcholine mediated aortic NO release in SHR or Wistar rats.

\section{Discussion}

\section{Effect of age and hypertension on NO level}

SHR differ in cardiovascular phenotypes from Wistar rats. They are characterized by endothelial dysfunction, i.e. reduced vascular reactivity, such as acetylcholine and adrenaline induced vasodilatation (Török et al. 2006, 2008, Dlugosova et al. 2009) and they are intolerable to age dependent NO deficiency (Arribas et al. 1994, Brooks et al. 2009, Rapoport et al. 1996, Radosinska et al. 2011, Tain et al. 2010, Török et al. 2008). These changes appear in SHR with respect to age. In 5-week-old SHR, vascular reactivity and NO release were preserved, whereas they were disturbed in 3-month-old SHR (Arribas et al. 1994, Török et al. 2006). Consistent to this, we found an increase in systolic blood pressure, decrease in plasma NO, loss of acetylcholine and adrenaline induced NO release in 10-month-old SHR. 
A

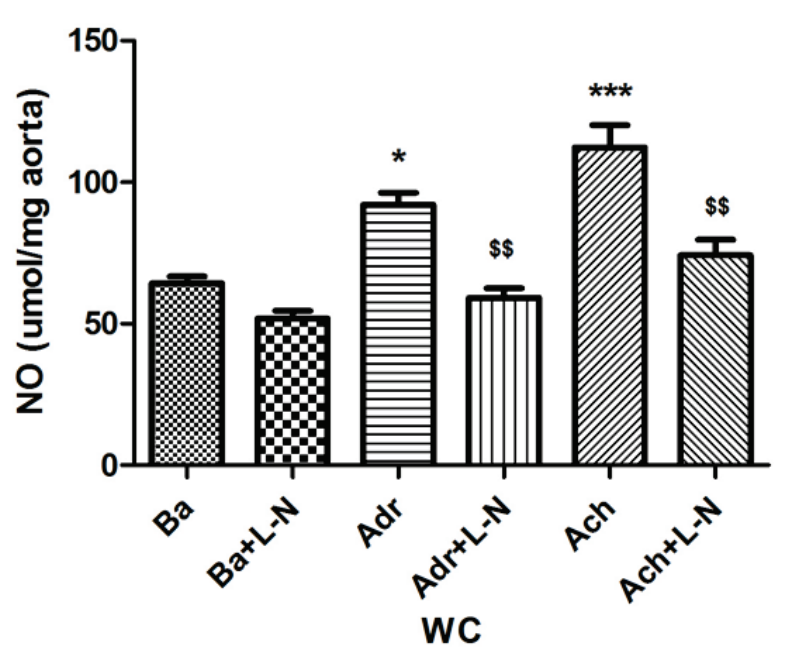

C

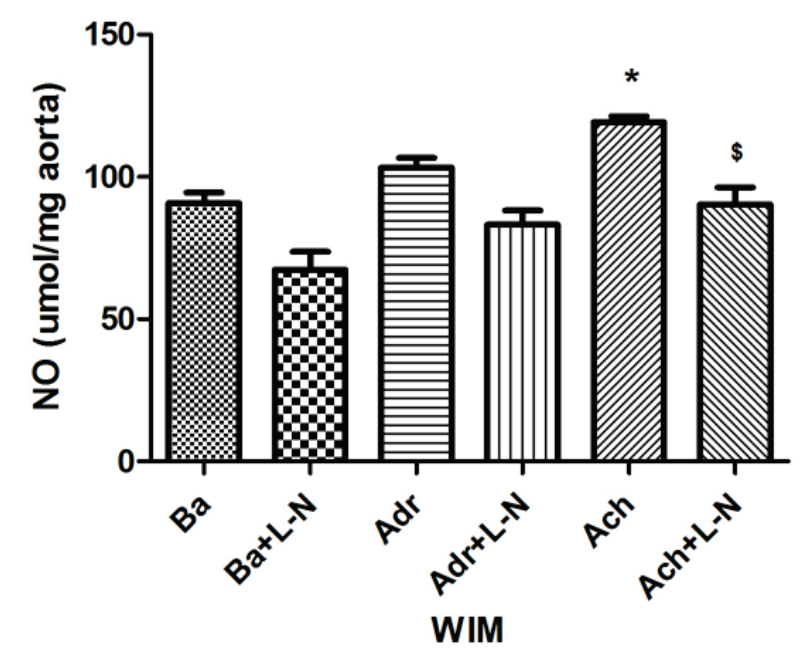

B

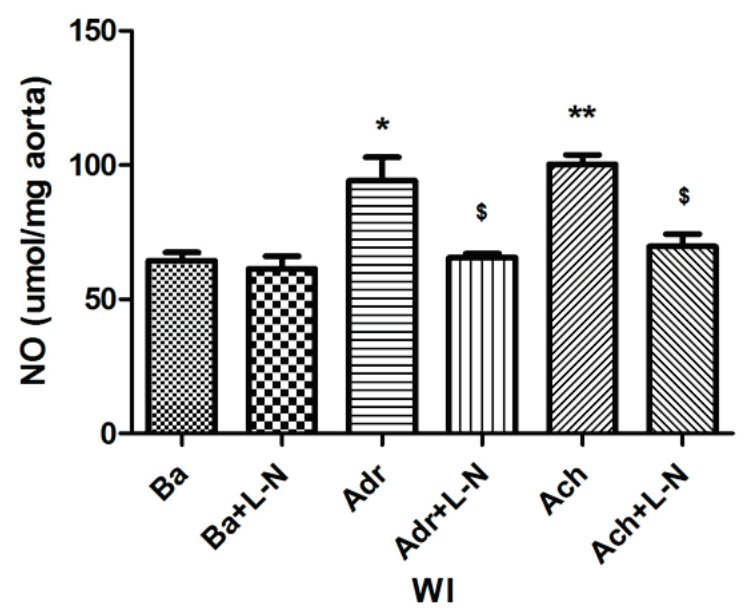

D

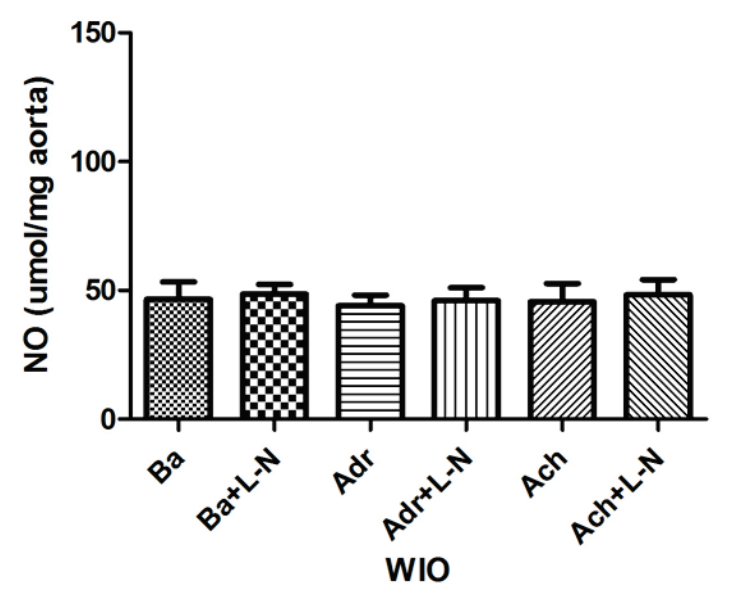

Fig. 4. Effect of L-NAME (NOS inhibitor) on basal (Ba), adrenaline (Adr) stimulated and acetylcholine (Ach) stimulated aortic NO release of experimental animals; (A) untreated Wistar rats (WC), (B) isoproterenol (Iso) treated WR (WI), (C) melatonin + Iso treated WR (WIM) and (D) PUFA + Iso treated WR (WIO). Values are expressed as mean \pm SEM. $* p<0.05, * * p<0.01$ and $* * * p<0.001$ vs. basal NO release. ${ }^{\$} p<0.05$ and ${ }^{\$} p<0.01$ vs. respective non L-NAME treated group.

In 14-, 17- and 63-week-old SHR, the expression and basal activity of eNOS (endothelial specific NOS) decreased, whereas basal activity and expression of iNOS (inducible NOS) increased in age matched SHR (Chou et al. 1998). Other reports suggested an increase in basal NO release from the aorta of SHR which was prominently attributed to iNOS (Maffei et al. 2002, Wu et al. 1999). In our study, the basal aortic NO release was similar in both strains, 10-month-old SHR and normotensive Wistar rats. It was independent from NOS activation. Acetylcholine and adrenaline induced aortic NO release, in our as well as other published studies, seems to be related to endothelial muscarinic receptor and $\beta$-adrenoceptor mediated NOS activation, respectively
(Arribas et al. 1994, Jen et al. 2002, Púzserová et al. 2013, Thioub et al. 2009).

\section{Effect of isoproterenol on NO level}

Besides age and hypertension, cardiac abnormalities may also alter vascular reactivity and NO bioavailability. Systemic vascular resistance was increased while adrenoceptor mediated NO release decreased in Wistar rats after the induction of myocardial infarction. It was related to the decrease in density of $\beta$-adrenoceptor (Gaballa et al. 2001). Acetylcholine mediated NO release was diminished in pulmonary and mesenteric arteries but not in aorta after development of heart failure in rats (Baggia et al. 1997). It points out 
a non-uniform response to injury throughout the vascular system. Accordingly, systemic NO levels may indicate abnormalities in systemic arteries other than aorta. Indeed, we found decrease in plasma NO in isoproterenol affected Wistar rats whereas aortic NO release was not altered. Apart from this, the $\beta$-adrenoceptor signaling and vascular non-uniformity might be altered due to ageing of SHR (Girouard et al. 2003). It may partially explain our findings that isoproterenol did not worsen plasma and aortic NO in 10-month-old SHR. It appears that vascular dysfunction can be differentially regulated by aging, hypertension and isoproterenol induced injury.
A

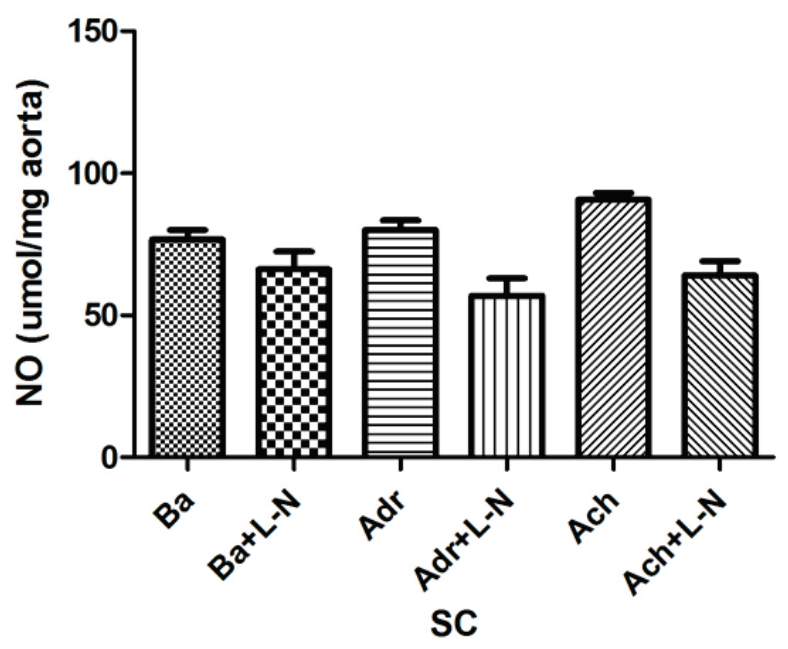

C

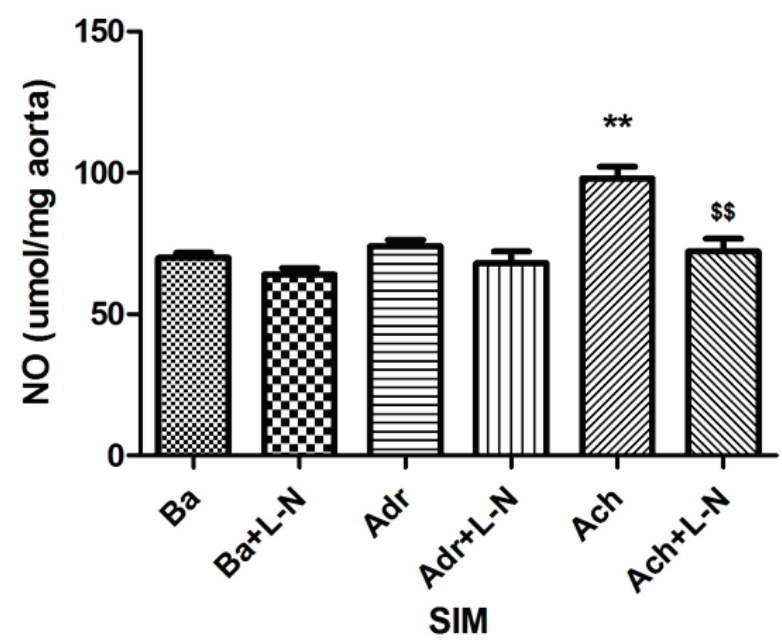

B

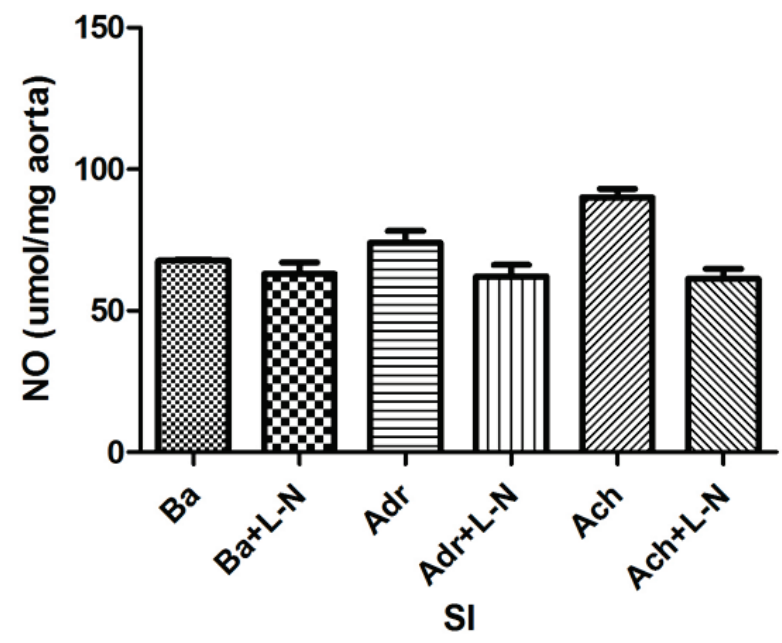

D

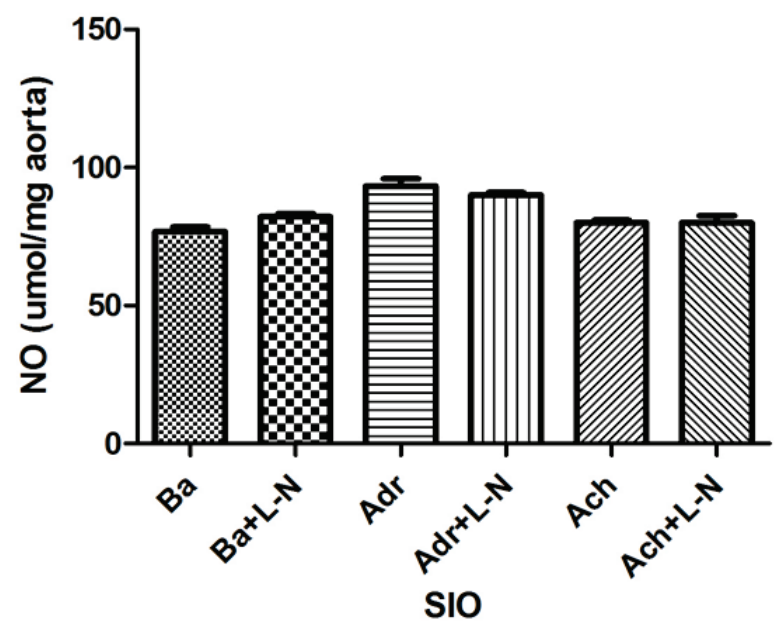

Fig. 5. Effect of L-NAME (NOS inhibitor) on basal (Ba), adrenaline (Adr) stimulated and acetylcholine (Ach) stimulated aortic NO release of experimental animals; (A) untreated SHR (SC), (B) Iso treated SHR (SI), (C) melatonin + Iso treated SHR (SIM) and (D) PUFA + Iso treated SHR (SIO). Values are expressed as mean \pm SEM. $* p<0.05, * * p<0.01$ and $* * * p<0.001$ vs. basal NO release. ${ }^{\$} p<0.05$ and $\$ \$ p<0.01$ vs. respective non L-NAME treated group.

Effect of melatonin on NO level in isoproterenol affected rats

Melatonin is a principal hormone of a pineal gland. Its production is modulated by age and hypertension. Juvenile SHR exhibited high plasma melatonin level and no elevation of systolic blood pressure unlike 15-week-old SHR that exhibited decrease of melatonin along with an increase in blood pressure in respect to age-matched normotensive Wistar Kyoto rats (Kawashima et al. 1984). The administration of melatonin (>30 mg/day for 4 weeks) decreased systolic blood pressure in 12-week-old SHR (Girouard et al. 2001). It was accomplished with an increase in acetylcholine-induced vasodilatation. In 23-week-old 
SHR, the antihypertensive action of melatonin was related to renin inhibition (Kawashima et al. 1987). In contrast, we did not find anti-hypertensive effect of melatonin in 10-month-old isoproterenol affected SHR. Most likely, it might be associated with a modulation of calcium homeostasis and dominant production of vasoconstrictor prostaglandins (Pogan et al. 2002). Melatonin increased intracellular calcium in presence of agonist and abolished superoxide linked suppression of calcium entry in endothelial cells (Pogan et al. 2002). Increase in intracellular calcium stimulates NOS dependent NO synthesis and cyclooxygenase mediated vasoconstrictor production. Age and hypertension are key factors for deciding dominancy of endothelial signaling pathways. Decrease in NOS dependent NO synthesis was associated with increase in systolic blood pressure at young age ( $<45$ years old) in hypertensive patients, whereas this was associated with cyclooxygenase mediated vasoconstrictor production at old age ( $>45$ years old) in hypertensive patients (Taddei et al. 1997). We found an increase in acetylcholine mediated NOS dependent NO synthesis in the aorta of both 10-month-old melatonin treated and isoproterenol affected SHR and normotensive Wistar rats, but no change in plasma NO. We can speculate about preservation of aortic NOS dependent NO production by melatonin in isoproterenol affected rats and dominancy of cyclooxygenase mediated vasoconstrictor production from other systemic arteries in blood pressure control of 10-month-old SHR. Adrenaline mediated NO release was not altered by melatonin in our study. It is in agreement with other reports, which have suggested ineffectiveness of melatonin to modulate isoproterenol induced vasorelaxation in mesenteric artery (Girouard et al. 2003) and decrease sympathetic tone by post synaptic modulation (K-Laflamme et al. 1998). In 10-month-old Wistar rats, melatonin treatment increased basal aortic NO release that was related to NOS independent NO synthesis. This increase in NO release may be related to thiol group increasing anti-oxidant property of melatonin (Zhao et al. 2015).

\section{Effect of PUFA on NO level in isoproterenol affected rats}

PUFA is a precursor of vasodilatating prostaglandins, 17,18-epoxyeicosatetraenoic acid and 19,20-epoxydocosapentaenoic acid, via enzymatic action of cytochrome P1A1. The genetic ablation of cytochrome P1A1 caused development of hypertension in normotensive rats (Agbor et al. 2012). Vasodilatatory prostaglandins stimulate adenosine triphosphate and calcium dependent $\mathrm{K}^{+}$-channel resulting in relaxation of vascular smooth muscles (Hoshia et al. 2013). Other than this, PUFA suppressed the agonist stimulated calcium release in the vascular smooth muscle (Engler et al. 2000, Hirafuji et al. 1998, Lawson et al. 1991). PUFA inhibits renin and sympathetic tone (Fischer et al. 2008). These actions might contribute to decrease of systolic blood pressure of 10-month-old SHR after PUFA treatment in our experiment. However, melatonin that also inhibited renin, adrenoceptor and modulated intracellular calcium homeostasis in endothelial cells (K-Laflamme et al. 1998, Kawashima et al. 1987, Pogan et al. 2002), did not alter systolic blood pressure in 10-month-old SHR. This suggests a prominent role of vasodilatatory prostaglandins dependent $\mathrm{K}^{+}$-channel activation for the anti-hypertensive action of PUFA in our study.

In the study of Dlugosova et al. (2009), PUFA reduced systolic blood pressure in SHR. It was independent from aortic NO release. The endothelial NOS dependent NO release was unaltered in the mesenteric artery and aorta of cytochrome P1A1 knock-out mice (Agbor et al. 2012). This suggested no NO modulating actions of PUFA vasodilatatory metabolites, 17,18-epoxyeicosatetraenoic acid and 19,20-epoxydocosapentaenoic acid. Eicosapentaenoic acid (EPA) and docosahaexanoic acid (DHA) inhibited endothelial NOS dependent NO synthesis in the aorta (Christon et al. 2005, Hirafuji et al. 1998). Consistent to this, we found fall in basal aortic NO, loss of acetylcholine and adrenaline induced aortic NO release after the PUFA treatment in normotensive isoproterenol treated Wistar rats. Argan oil, EPA and DHA-rich oil increased NO in the tissue by enhancing the level of antioxidants and abolishing superoxide production (Berrougui et al. 2004). Anti-oxidant property of PUFA contributed to the increase in plasma NO of 10-month-old isoproterenol affected SHR. Thus, antihypertensive action of PUFA in SHR seems also to be related to the increase of systemic NO.

\section{Conclusion}

Findings of our study suggest that systemic rather than aortic NO is a decisive factor contributing to modulation of blood pressure in hypertensive rat disease. PUFA, but not melatonin, would be a preferable treatment to decrease blood pressure by restoring 
systemic NO in aged hypertensive subjects. Melatonin preserves acetylcholine induced NO level but inhibits adrenaline action in aorta of aged spontaneously hypertensive rats.

\section{Conflict of Interest}

There is no conflict of interest.

\section{Acknowledgements}

This study was supported by SAIA, VEGA 2/0076/16, 2/0167/15 and APVV-0348-12 grants.

\section{References}

AGBOR L, WALSH M, BOBERG J, WALKER M: Elevated blood pressure in cytochrome P4501A1 knockout mice is associated with reduced vasodilation toomega-3 polyunsaturated fatty acids. Toxicol Appl Pharmacol 264: 351-360, 2012.

ARRIBAS S, MARÍN J, PONTE A, BALFAGÓN G, SALAICES M: Norepinephrine-induced relaxations in rat aorta mediated by endothelial beta adrenoceptors. Impairment by ageing and hypertension. J Pharmacol Exp Ther 270: 520-527, 1994.

BAGGIA S, PERKINS K, GREENBERG B: Endothelium-dependent relaxation is not uniformly impaired in chronic heart failure. J Cardiovasc Pharmacol 29: 389-396, 1997.

BENOVA T, VICZENCZOVA C, RADOSINSKA J, BACOVA B, KNEZL V, DOSENKO V, WEISMANN P, ZEMAN M, NAVAROVA J, TRIBULOVA N: Melatonin attenuates hypertension-related proarrhythmic myocardial maladaptation of connexin-43 and propensity of the heart to lethal arrhythmias. Can J Physiol Pharmacol 91: 633-639, 2013.

BERrougui H, ALVAREZ DE SOTOMAYOR M, PÉREZ-GUERRERO C, ETTAIB A, HMAMOUCHI M, MARHUENDA E, HERRERA M: Argan (Arganiaspinosa) oil lowers blood pressure and improves endothelial dysfunction in spontaneously hypertensive rats. Br J Nutr 92: 921-929, 2004.

BORGHI C, CICERO A: Omega-3 polyunsaturated fatty acids: their potential role in blood pressure prevention and management. Heart Int 2: 98-105, 2006.

BROOKS W, CONRAD C, ROBINSON K, COLUCCI W, BING O: L-arginine fails to prevent ventricular remodeling and heart failure in the spontaneously hypertensive rat. Am J Hypertens 22: 228-234, 2009.

CHAUDAGAR K, MEHTA A: Effect of atorvastatin on the angiogenic responsiveness of coronary endothelial cells in normal and streptozotocin (STZ) induced diabetic rats. Can J Physiol Pharmacol 92: 338-349, 2014.

CHOU T, YEN M, LI C, DING Y: Alterations of nitric oxide synthase expression with aging and hypertension in rats. Hypertension 31: 643-648, 1998.

CHRISTON R, MARETTE A, BADEAU M, BOURGOIN F, MÉLANÇON S, BACHELARD H: Fatty acid-induced changes in vascular reactivity in healthy adult rats. Metabolism 54: 1600-1609, 2005.

DLUGOSOVA K, OKRUHLICOVA L, MITASIKOVA M, SOTNIKOVA R, BERNATOVA I, WEISMANN P, SLEZAK J, TRIBULOVA N: Modulation of connexin-43 by omega-3 fatty acids in the aorta of old spontaneously hypertensive rats. J Physiol Pharmacol 60: 63-69, 2009.

ENGLER M, ENGLER M, BROWNE A, SUN Y, SIEVERS R: Mechanisms of vasorelaxation induced by eicosapentaenoic acid (20:5n-3) in WKY rat aorta. Br J Pharmacol 131: 1793-1799, 2000.

FISCHER R, DECHEND R, QADRI F, MARKOVIC M, FELDT S, HERSE F, PARK J, GAPELYUK A, SCHWARZ I, ZACHARZOWSKY U, PLEHM R, SAFAK E, HEUSER A, SCHIRDEWAN A, LUFT F, SCHUNCK W, MULLER D: Dietary n-3 polyunsaturated fatty acids and direct renin inhibition improve electrical remodeling in a model of high human renin hypertension. Hypertension 51: 540-546, 2008.

GABALLA M, ECKHART A, KOCH W, GOLDMAN S: Vascular beta-adrenergic receptor system is dysfunctional after myocardial infarction. Am J Physiol Heart Circ Physiol 280: H1129-H1135, 2001.

GIROUARD H, CHULAK C, LEJOSSEC M, LAMONTAGNE D, DE CHAMPLAIN J: Vasorelaxant effects of the chronic treatment with melatonin on mesenteric artery and aorta of spontaneously hypertensive rats. J Hypertens 19: 1369-1377, 2001. 
GIROUARD H, CHULAK C, LEJOSSEC M, LAMONTAGNE D, DE CHAMPLAIN J: Chronic antioxidant treatment improves sympathetic functions and beta-adrenergic pathway in thespontaneously hypertensive rats. J Hypertens 21: 179-188, 2003.

HIRAFUJI M, EBIHARA T, KAWAHARA F, MINAMI M: Effect of docosahexaenoic acid on smooth muscle cell functions. Life Sci 62: 1689-1693, 1998.

HOSHIA T, WISSUWA B, TIAN Y, TAJIMA N, XU R, BAUER M, HEINEMANN S, SHANGWEI HOU S: Omega-3 fatty acids lower blood pressure by directly activating large-conductance $\mathrm{Ca} 2+$-dependent $\mathrm{K}+$ channels. Proc Natl Acad Sci USA 110: 4816-4821, 2013.

JEN C, CHAN H, CHEN H: Acute exercise enhances vasorelaxation by modulating endothelial calcium signaling in rat aortas. Am J Physiol Heart Circ Physiol 282: H977-H982, 2002.

K-LAFLAMME A, WU L, FOUCART S, DE CHAMPLAIN J: Impaired basal sympathetic tone and alpha1-adrenergic responsiveness in association with the hypotensive effect of melatonin in spontaneously hypertensive rats. $\mathrm{Am}$ J Hypertens 11: 219-229, 1998.

KAWASHIMA K, NAGAKURA A, WURZBURGER R, SPECTOR S: Melatonin in serum and the pineal of spontaneously hypertensive rats. Clin Exp Hypertens 6: 1517-1528, 1984.

KAWASHIMA K, MIWA Y, FUJIMOTO K, OOHATA H, NISHINO H, KOIKE H: Antihypertensive action of melatonin in the spontaneously hypertensive rat. Clin Exp Hypertens 9: 1121-1131, 1987.

LAWSON D, MEHTA J, SALDEEN K, MEHTA P, SALDEEN T: Omega-3 polyunsaturated fatty acids augment endothelium-dependent vasorelaxation by enhanced release of EDRF and vasodilator prostaglandins. Eicosanoids 4: 217-223, 1991.

MAFFEI A, POULET R, VECCHIONE C, COLELLA S, FRATTA L, FRATI G, TRIMARCO V, TRIMARCO B, LEMBO G: Increased basal nitric oxide release despite enhanced free radical production in hypertension. J Hypertens 20: 1135-1142, 2002.

MANO M, BEXIS S, ABEYWARDENA M, MCMURCHIE E, KING R, SMITH R, HEAD R: Fish oils modulate blood pressure and vascular contractility in the rat and vascular contractility in the primate. Blood Press 4 : 177-186, 1995.

MANSO A, ENCABO A, REDONDO J, SALAICES M, MARÍN J: Different sensitivity of isoprenaline-induced responses in ventricular muscle to sodium nitroprusside in normotensive and spontaneously hypertensive rats. J Auton Pharmacol 20: 77-85, 2000.

MENDIS S, PUSKA P, NORRVING B: What are cardiovascular diseases (CVDs)? In: Global Atlas on Cardiovascular Disease Prevention and Control: Policies, Strategies and Interventions. World Health Organisation, World Heart Federation, World Stroke Organization, Geneva, 2011, pp 2-7.

PANZA J, GARCÍA C, KILCOYNE C, QUYYUMI A, CANNON R: Impaired endothelium-dependent vasodilation in patients with essential hypertension. Evidence that nitric oxideabnormality is not localized to a single signal transduction pathway. Circulation 91: 1732-1738, 1995.

PECHÁNOVÁ O, ZICHA J, PAULIS L, ZENEBE W, DOBESOVÁ Z, KOJSOVÁ S, JENDEKOVÁ L, SLÁDKOVÁ M, DOVINOVÁ I, SIMKO F, KUNES J: The effect of N-acetylcysteine and melatonin in adult spontaneously hypertensive rats with established hypertension. Eur J Pharmacol 561: 129-136, 2007.

POGAN L, BISSONNETTE P, PARENT L, SAUVÉ R: The effects of melatonin on Ca(2+) homeostasis in endothelial cells. J Pineal Res 33: 37-47, 2002.

PÚZSEROVÁ A, KOPINCOVÁ J, SLEZÁK P, BALIŠ P, BERNÁTOVÁ I: Endothelial dysfunction in femoral artery of the hypertensive rats is nitric oxide independent. Physiol Res 62: 615-629, 2013.

RADOSINSKA J, BACOVA B, BERNATOVA I, NAVAROVA J, ZHUKOVSKA A, SHYSH A, OKRUHLICOVA L, TRIBULOVA N: Myocardial NOS activity and connexin-43 expression in untreated and omega-3 fatty acids-treated spontaneously hypertensive and hereditary hypertriglyceridemic rats. Mol Cell Biochem 347: 163-173, 2011.

RAPOPORT R, WILLIAMS S: Role of prostaglandins in acetylcholine-induced contraction of aorta from spontaneously hypertensive and Wistar-Kyoto rats. Hypertension 28: 64-75, 1996.

SIMKO F, PAULIS L: Melatonin as a potential antihypertensive treatment. J Pineal Res 42: 319-322, 2007. 
TADDEI S, VIRDIS A, MATTEI P, GHIADONI L, FASOLO C, SUDANO I, SALVETTI A: Hypertension causes premature aging of endothelial function in humans. Hypertension 29: 736-743, 1997.

TAIN Y, HUANG L, LIN I, LAU Y, LIN C: Melatonin prevents hypertension and increased asymmetric dimethylarginine in young spontaneous hypertensive rats. J Pineal Res 49: 390-398, 2010.

THIOUB S, MANSOURATI J, CORPOREAU C, HEYLEN E, DELARUE J, GUERRERO F: Effects of n-3 fatty acids and acute exercise on endothelium-dependent vasorelaxation in healthy rat aorta. Br J Nutr 101: 829-835, 2009.

TÖRÖK J: Participation of nitric oxide in different models of experimental hypertension. Physiol Res 57: 813-825, 2008.

TÖRÖK J, KOPRDOVÁ R, CEBOVÁ M, KUNES J, KRISTEK F: Functional and structural pattern of arterial responses in hereditary hypertriglyceridemic and spontaneously hypertensive rats in early stage of experimental hypertension. Physiol Res 55 (Suppl 1): S65-S71, 2006.

VÁZQUEZ-PÉREZ S, NAVARRO-CID J, DE LAS HERAS N, CEDIEL E, SANZ-ROSA D, RUILOPE L, CACHOFEIRO V, LAHERA V: Relevance of endothelium-derived hyperpolarizing factor in the effects of hypertension on rat coronary relaxations. J Hypertens 19: 539-545, 2001.

WU C, YEN M: Higher level of plasma nitric oxide in spontaneously hypertensive rats. Am J Hypertens 12: 476-482, 1999.

ZHANG G, KIMURA S, NISHIYAMA A, SHOKOJI T, RAHMAN M, YAO L, NAGAI Y, FUJISAWA Y, MIYATAKE A, ABE Y: Cardiac oxidative stress in acute and chronic isoproterenol-infused rats. Cardiovasc Res 65: 230-238, 2005.

ZHANG J, KNAPTON A, LIPSHULTZ S, WEAVER J, HERMAN E: Isoproterenol-induced cardiotoxicity in spraguedawley rats: correlation of reversible and irreversible myocardial injury with release of cardiac troponin $\mathrm{T}$ and roles of iNOS in myocardial injury. Toxicol Pathol 36: 277-288, 2008.

ZHAO Y, VANHOUTTE P, LEUNG S: Vascular nitric oxide: beyond eNOS. J Pharmacol Sci 129: 83-94, 2015. 